\title{
Prevalence and factors associated with low lumbar strength in adolescents
}

Open acess

${ }^{1}$ Universidade Federal de Santa

Catarina, Florianópolis, SC, Brasil.

Corresponding author:

elianeandradegoncalves@gmail.com

Manuscript received: 21 March 2017 Manuscript accepted: 20 June 2017

Version of record online:06 September 2017

\author{
Eliane Cristina de Andrade Gonçalves1, Diego Augusto Santos \\ Silva ${ }^{1}$
}

\begin{abstract}
Introduction: Low back pain is a multifactorial disorder and is one of the most common musculoskeletal discomfort in adolescents and adults.
\end{abstract}

Objective: To determine the prevalence and factors associated with low levels of lumbar force in adolescents.

Methods: This is a cross-sectional study involving 909 adolescents aged 14 to 19 years enrolled in public schools in São José, of Santa Catarina State - Southern Brazil. Lumbar force was analyzed by the lumbar extension test developed by a Canadian research group, which proposes different cutoffs according sex. Independent variables were sex, age, socioeconomic status, alcohol consumption, screen time, physical activity, aerobic fitness and mass body index. For data analysis, binary logistic regression was used, with significance level of $5 \%$.

Results: The prevalence of low levels of lumbar force was $45.2 \%$, being $36.2 \%$ for boys and $53.1 \%$ for girls. The population subgroups most likely to present low levels of lumbar force were females (OR: 1,99; Cl95\%: $1,52$ to 2,60$)$ and those adolescents with overweight (OR: 1,$48 ; \mathrm{Cl} 95 \%: 1,12$ to 1,96 ).

Conclusion: Almost half of the students had low levels of lumbar force. The girls, the adolescents with overweight and with excessive time in front of the screen most likely present low levels of lumbar force. The innovation of this study is modifiable factors such as the excessive time screen and overweight may be used to promote health interventions to improve levels of lumbar strength of youth.

Keywords: motor activity, physical fitness, low back pain, adolescent health, spine, pain. 


\section{INTRODUCTION}

Low back pain is a multifactorial disorder, with a diagnosis that is not always specific and is one of the most common musculoskeletal discomforts in adolescents and adults ${ }^{1}$. It reached $9.4 \%$ of the world population in $2010^{2}$, and for young population, studies presented variability in the estimated prevalence from $14 \%$ to $24 \%$ between 1991 and $2009^{3}$. In Brazil, a systematic review revealed the prevalence of adolescents with lumbar complaints ranged from $13.1 \%$ to $19 \%$ between 2005 and 2011 , respectively ${ }^{4}$.

The most frequent causes of low back pain in adolescents are usually related to the growing burden of inadequate support of school backpacks and prolonged sitting for long periods of time ${ }^{1}$. In addition, studies indicate that female and adolescents with inadequate lifestyle habits such as physical inactivity, sedentary behavior and overweight are the subgroups vulnerable to frequent low back complaints among adolescents ${ }^{5,6}$.

Surveys have shown that another possible cause of low back pain is associated with low levels of lumbar force ${ }^{7-9}$. A cohort study evaluated 215 Portuguese schoolchildren concluded that low levels of muscle strength of the trunk extensors/flexors were associated with a higher prevalence of low back pain and low flexibility of the posterior thigh muscles ${ }^{10}$. Similar results were found in another study 9

\section{METHODS}

This is a cross-sectional analytical study of school base, part of the macroproject "Guia Brasileiro deAvaliação da Aptidão Física Relacionada à Saúde e Hábitos de Vida - Etapa I" - Protocol CAAE: 33210414.3.0000.0121 and was developed between August and November 2014.

The population $(\mathrm{N}=5182)$ was composed of adolescents aged 14 to 19 enrolled in state public schools in the city of São José, Santa Catarina (SC) State, Brazil, which has 209,804 inhabitants and a Municipal Human Development Index of 0.809. São José city makes territorial boundary with the city of Florianópolis and together they form the most populous metropolitan region of SC State, Brazil. The school space, besides being an environment conducive to encouraging the adoption of a healthy and active lifestyle, is a place where young people spend much of their time. Thus, the choice of students in public institutions is justified because the schools and the neighbourhoods where they are located present social, cultural and economic discrepancies, allowing the identification of adolescents of different cultures, ethnicities and customs.

The sample process was determined in two stages: 1) stratified by state public high schools $(n=11)$; 2$)$ group conglomerate considering study shift and school grade ( $n=170$ classes). In stage 2, all high school students who were present in the classroom on the days of data collection were invited to participate in the study.

For the sample calculation, we adopted an unknown prevalence for the outcome (50\%), a tolerable error of five percentage points, a $95 \%$ confidence interval, a delineation effect of 1.5 , adding $20 \%$ for losses and refusals, and
These data are worrying considering that individuals with low levels of lumbar force and frequent back pain ${ }^{9}$ are more likely to develop various disorders such as postural deviations ${ }^{8}$, musculoskeletal diseases and excess weight, leading to an increased risk of premature death $^{11}$. In addition, studies on low levels of lumbar force ${ }^{4}$ are still scarce, mainly relating sociodemographic factors, economic level and lifestyle.

Thus, it is important to stand out the relevance of analyzing the prevalence of low levels of lumbar force and the possible correlated factors, in order to guide the planning of lumbar strengthening programs according to the reality found, considering that adolescents with low levels of lumbar forces present difficulties in social life and low quality of life $\mathrm{e}^{10,12}$. In addition, this aggravation generates considerable public expenditures, reaching more than 86 billion dollars annually for treatment and rehabilitation ${ }^{13}$. This study is justified because it will contribute with the epidemiological knowledge of the subject. Therefore, the objective is to analyze the associated factors and estimate the prevalence of low levels of lumbar force in adolescents.

a further $20 \%$ for association study. A sample of 751 adolescents was estimated. However, due to conglomerate sampling, all students in the classes were invited to participate in the study, resulting in 1,148 students with data collected, of them 16 individuals were excluded because they were over 19 years old, totaling 1,132. It was defined as eligible to be enrolled in the state education network, be in the classroom on the day of collection and between 14 and 19 years old. It was considered as refusal the adolescent who did not want to participate in the research and as sample loss the questionnaire not filled out or those adolescents who did not perform one or more physical tests.

The dependent variable was lumbar force. The test used to evaluate lumbar strength levels is an isometric test proposed by the group of Canadian Physical Activity, Fitness and Lifestyle Approach (CPAFLA) ${ }^{14}$ with predictive validity for lumbar pain ${ }^{15}$. The test of extension and support of the trunk, dorsal isometric, was performed on a bench in which the evaluated one lies down in ventral position, only the legs and the hip were in contact with the bench. A prepared rope supports the legs with padding in the posterior regions of the thigh and leg. At the evaluator's signal, the participant raised the trunk horizontally with the legs, remaining for the maximum time the person was able to maintain this position. The test was terminated when the participant held the torso or held it up to a maximum of three minutes (180 seconds). The Canadian protocol ${ }^{15}$ determines five ratings for this test, which varies by gender and age: (A) "Needs improvement"; (B) "Regular"; (C) "Good"; (D) "Very good"; (E) "excellent". In this study, 
the level of lumbar force was considered "adequate" for adolescents in categories (c), (d), (e) and "inappropriate" for categories (a) and (b).

The sociodemographic and lifestyle variables were collected through a self-administered questionnaire, and the question about the level of physical activity was taken from the Youth Risk Behaviour Survey, translated and validated for Brazil ${ }^{16}$. Age was categorized as "1416 years" and "17-19 years". The economic level was identified by Brazilian Association of Research Companies (ABEP) and dichotomized in "High" ("A1", "A2", "B1", "B2") and "Low" (“C1”, “C2”, “D”, "E”).

Screen time analysis was performed by six different questions, which verified the amount of hours spent in front of the television, computer and video game, weekly and on weekends. The screen time was calculated by the sum of the hours spent in front of the screen during working days (calculated by multiplying the hours and minutes by five) and at the weekend (calculated by multiplying the hours and minutes by two), resulting in the full time of screen. The daily average of hours was verified by the sum of the hours in the seven days of the week divided by the total of days of the week (seven days) for the three types of electronics (television, computer and video game). The categories were "adequate" $(<2$ hours per day) and "inadequate" ( $\geq 2$ hours per day $)^{17}$.

The question about practicing physical activity was, "During the past seven days, how many days have you been physically active for at least 60 minutes daily?" Adolescents who practiced physical activity five days or more weekly were classified as "physically active $(\geq$ 300 minutes per week)" and less than five days/week as "physically un-active (<300 minutes per week)".

Aerobic fitness was measured using the modified Canadian Aerobic Fitness test - Mcaft ${ }^{14}$, validated in comparison with indirect calorimetric in Canadian men and women aged 15-69 years ${ }^{18}$. The adolescents had to complete one or more stages of three minutes each (ascending and descending two steps of 20.3 centimetres each with increase of intensity) in predetermined cadences according to sex and age. The test was finalized only when the subject reached $85 \%$ of the maximal heart rate (recommended by the 220 -age formula) ${ }^{14}$ which was measured using the Polar ${ }^{\circledR}$ brand H7 Bluetooth Frequencimeter (Kempele, Finland). For the adolescents who completed at least one stage, but stopped in the middle of the other, was counted as final stage the previous stage.

Oxygen expenditure and reference values for aerobic fitness were determined by the Canadian battery tests $^{15}$. The equation of the aerobic fitness score is: Score= $10[17.2+(1.29 \times$ Oxygen expenditure $)-(0.09 \times$ weight in $\mathrm{kg})-(0.18 \mathrm{x} \text { age in years })^{19-21}$. From this score, each participant was classified in one of five categories: (A) "Needs improvement"; (B) "Regular"; (C) "Good"; (D) "Very good"; (E) "Excellent". The adolescents in categories (c), (d), (e) were considered to have "adequate" aptitude and, for categories (a) and (b), "inadequate" aptitude.

In order to obtain the BMI measure (body mass in kilograms/height in meters ${ }^{2}$ ), the standardization of the International Society for the Advancement of Kinanthropometry (ISAK) to measure body mass and height, classifying individuals according to the cut-off points of the World Health Organization that considers sex and age ${ }^{22}$. BMI was dichotomized in "normal weight" (low weight and eutrophic) and "overweight" (overweight and obesity).

In the descriptive analysis of the variables were used means, standard deviations and frequency distribution. The normality of the data was verified through histograms of sample distribution, however, no variable had a normal distribution. To identify differences in the prevalence of low levels of lumbar force according to the independent variables, the chi-square test of heterogeneity was applied.

Binary logistic regression was used to examine the associations between outcome with socio-demographic indicators (sex, age, economic level), lifestyle (screen time and physical activity), aerobic fitness and presence of excess weight, estimating the odds ratio (OR) and the $95 \%$ confidence interval. All variables were introduced in the independent adjusted p-value model in the crude analysis. The variables that presented $\mathrm{p}<0.05$ were considered associated with the outcome. The level of significance was set at $5 \%$.

The analyses were performed in Stata 11.0 software (STATA Corp. College Station, Texas USA), considering the design effect and the sample weight. The results were not stratified by sex because there was no interaction between sex and outcome.

\section{RESULTS}

Of the 1,132 students, 223 were excluded from the analyses because they did not perform the lumbar force test, resulting in 909 students with a mean of $16.22 \pm 1.14$ years of age, predominantly female adolescents (54.2\%). Table 1 shows mean values and standard deviation of age, anthropometric variables, BMI, aerobic fitness and muscular endurance in the lumbar force test. The boys had higher values than the girls for height, aerobic fitness and muscle endurance time in the lumbar force test $(\mathrm{p}<0.01)$. There were no differences between the gender for age, body mass and BMI.

Table 1. Mean values and standard deviation of age, anthropometric variables, aerobic fitness and endurance time in the lumbar force test according to sex.

\begin{tabular}{lcccc}
\hline Variables & Total sample & Male & Female & p-value \\
& M \pm SD & M \pm SD & M \pm SD & \\
\hline Age years) & $16.22 \pm 1.14$ & $16.28 \pm 1.19$ & $16.16 \pm 1.10$ & 0.15
\end{tabular}




\begin{tabular}{|c|c|c|c|c|}
\hline Body mass $(\mathrm{kg})$ & $61.67 \pm 12.20$ & $65.43 \pm 12.07$ & $58.31 \pm 11.32$ & 0.25 \\
\hline Height (cm) & $166.56 \pm 8.81$ & $172.59 \pm 7.35$ & $161.17 \pm 6.09$ & $<0.01^{*}$ \\
\hline BMI $\left(\mathrm{kg} / \mathrm{m}^{2}\right)$ & $22.21 \pm 3.82$ & $21.89 \pm 3.44$ & $22.41 \pm 3.95$ & 0.25 \\
\hline Aerobic score & $388.05 \pm 58.34$ & $426.82 \pm 53.46$ & $353.37 \pm 36.69$ & $<0.01^{*}$ \\
\hline $\begin{array}{l}\text { Lumbar force test } \\
\text { (seconds) }\end{array}$ & $122.98 \pm 51.99$ & $131.24 \pm 49.44$ & $115.70 \pm 53.13$ & $<0.01^{*}$ \\
\hline
\end{tabular}

Legend: M: mean; SD: standard deviation; BMI: body mass index; * $\mathrm{P} \leq 0.05$ ( $\mathrm{p} \leq 0.05$ (Mann Whitney U test).

Table 2 shows that the majority of the sample was 14-16 years old and had a high economic level. Of the students investigated, more than half of the sample was overweight. Eight out of ten adolescents presented excessive screen time, $76.4 \%$ were poorly active and $45.8 \%$ had low aerobic fitness. Girls and those boys who were overweight had worse performance of muscle strength of lumbar force $(p<0.01)$. In addition, females and those boys who were overweight had higher prevalences of having low levels of lumbar force $(p<0.05)$.

Both in the raw and in the adjusted analysis, those overweight adolescents were more likely to have low lumbar force. In the crude analysis girls were less likely to have low lumbar force. In the adjusted analysis, girls were more likely to have low lumbar force (Table 3 ).

Table 2. Sample distribution, muscle endurance time in the lumbar force test and prevalence of low lumbar force levels according to the independent variables among adolescents.

\begin{tabular}{|c|c|c|c|}
\hline Variables & $\begin{array}{l}\text { Sample } \\
\mathrm{n}(\%)\end{array}$ & $\begin{array}{l}\text { Endurance time (seconds) } \\
\qquad \mathrm{M} \pm \mathrm{SD}\end{array}$ & $\begin{array}{l}\text { Prevalence of low lumbar force } \\
\qquad \%(\text { IC } 95 \%)\end{array}$ \\
\hline Total & $910(100)$ & $122,9(51,99)$ & $45,2(41,9-48,4)$ \\
\hline Sex & & $p<0,01^{*}$ & $p<0,01 \dagger$ \\
\hline Male & $519(45,8)$ & $131,2 \pm 49,4$ & $36,2(31,7-40,9)$ \\
\hline Female & $613(54,2)$ & $115,7 \pm 53,1$ & $53,1(48,6-57,2)$ \\
\hline Age years) & & $p=0,86$ & $p=0,79$ \\
\hline $14-16$ & $506(57,6)$ & $123,1 \pm 50,4$ & $45,5(41,3-49,9)$ \\
\hline $17-19$ & $373(42,4)$ & $122,7 \pm 54,0$ & $44,7(39,7-49,7)$ \\
\hline Economic level & & $p=0,61$ & $p=0,46$ \\
\hline High & $503(67,8)$ & $123,9 \pm 51,4$ & $44,1(39,9-59,2)$ \\
\hline Low & $239(32,2)$ & $122,1 \pm 52,24$ & $46,9(40,7-53,2)$ \\
\hline Screen time & & $p=0,23$ & $p=0,24$ \\
\hline Suitable & $148(13,8)$ & $128,4 \pm 51,57$ & $39,5(31,2-48,4)$ \\
\hline Inappropriate & $922(86,2)$ & $123,4 \pm 51,72$ & $45,1(41,5-48,7)$ \\
\hline Physical activity & & $p=0,23$ & $p=0,41$ \\
\hline Physically active ( $\geq 300$ minutes) & $202(23,6)$ & $127,4 \pm 50,4$ & $42,5(36,0-49,4)$ \\
\hline \multicolumn{4}{|l|}{ Little physically active } \\
\hline (<300 minutes) & $653(76,4)$ & $121,9 \pm 52,4$ & $45,7(42,0-49,5)$ \\
\hline Aerobic Fitness & & $p=0,16$ & $p=0,38$ \\
\hline Suitable & $326(54,2)$ & $128,8 \pm 55,46$ & $40,3(31,4-44,9)$ \\
\hline Inappropriate & $275(45,8)$ & $123,7 \pm 50,2$ & $44,8(41,3-48,3)$ \\
\hline Weight Status & & $p<0,01^{*}$ & $p=0,03 \dagger$ \\
\hline Normal & $453(44,9)$ & $130,4 \pm 51,77$ & $39,3(34,6-44,1)$ \\
\hline Overweight & $555(55,1)$ & $118,4 \pm 50,1$ & $49,3(44,9-53,6)$ \\
\hline
\end{tabular}

Legend: M: average; SD: standard deviation; Cl: confidence interval; * $\mathrm{P}<0.05$ - Mann Whitney $\mathrm{U}$ test; $\dagger p<0.05$ - chi-square test of heterogeneity.

Table 3. Odds ratios and 95\% confidence intervals, crude and adjusted, between low lumbar force levels and independent variables.

\begin{tabular}{|c|c|c|c|c|}
\hline \multirow[t]{2}{*}{ Variables } & \multirow{2}{*}{$\begin{array}{c}\text { Gross Analysis } \\
\text { OR (IC95\%) }\end{array}$} & \multicolumn{3}{|c|}{ Adjusted Analysis $†$} \\
\hline & & p-value & OR (IC95\%) & $\mathrm{p}$-value \\
\hline \multicolumn{5}{|l|}{ Sex } \\
\hline Male & 1,00 & $<0,01^{*}$ & 1,00 & $<0,01^{*}$ \\
\hline Female & $0,50(0,38-0,65)$ & & $2,10(1,59-2,79)$ & \\
\hline \multicolumn{5}{|c|}{ Age (years) ${ }^{a}$} \\
\hline $14-16$ & 1,00 & 0,79 & 1,00 & 0,93 \\
\hline
\end{tabular}


17-19

$0,96(0,74-1,25)$

Economic level

High
Low
Telab tim

Telab time

Suitable

Inappropriate

Physical Activity

Active

Insufficiently active

Aerobic Fitness

Suitable

Inappropriate

Weight Status ${ }^{\mathrm{c}}$

Normal

Overweight
1,00

$1,12(0,82-1,51)$

1,00

$1,26(0,85-1,85)$

1,00

$1,13(0,83-1,55)$

1,00

$1,20(0,79-1,80)$

1,00

$1,50(1,51-1,96)$
$0,48(0,70-1,37)$

1,00

$0,97(0,70-1,35)$

1,00

0,04 *

$1,51(1,01-2,26)$

1,00

$0,98(0,70-1,37)$

1,00

0,86

$0,95(0,59-1,55)$

1,00

$<0,01^{*}$

Legend: OR: odds ratio; $\mathrm{Cl}$ : confidence interval; ${ }^{*} \mathrm{P} \leq 0.05$; $\uparrow$ analysis adjusted by all independent variables. Overwritten letters: ${ }^{\mathrm{a}}$ - variables from the level distal to the outcome; ${ }^{{ }^{B}}$ intermediate level variables; ${ }^{C_{-}}$variables from the level proximal to the outcome.

\section{DISCUSSION}

The main finding of this research was almost half of the sample presented low levels of lumbar force. The subgroups most likely to have low levels of lumbar force were females, those who had excessive screen time and were overweight.

The prevalence found for the low level of lumbar force of adolescents was $45.2 \%$, similar to studies carried out with students from southern Brazil ${ }^{6,23}$. This finding is worrying because low rates of lumbar force have been reported in the literature as a risk factor for the development of some dysfunctions such as low back pain and postural distortions in different age groups, increasing the chances of lumbar complaints ${ }^{2-4,12}$. Therefore, it is important that adolescents receive guidelines encouraging the regular practice of physical activity in order to improve physical fitness and muscular strength and endurance. As an example of this importance, after an intervention with young adults (mean age of 27 years) aimed to investigate the effects of six weeks of exercise training on the levels of pain, disability and muscular strength/endurance of individuals with low back pain it was observed the muscle strength/endurance levels were significantly higher after the intervention?

The results of this study support theories ${ }^{12,24}$ that indicate an association between low level of lumbar force and the female sex ${ }^{12,24}$. This fact happens because, generally, regular physical activity in adolescence is more exercised by boys, through games, and competitive sports, which provides improvement in muscle strength/ endurance ${ }^{25}$. In addition, hormonal differences arising from the maturational process in the adolescence phase provide a better performance in physical tests by the boys compared to the girls ${ }^{25,26}$. Therefore, it is important to encourage, especially in females, the regular practice of physical activity in order to improve and possibly develop better levels of lumbar force.

Excessive screen time was associated with low levels of lumbar force. A study of 3,600 schoolchildren in
Shanghai, China, found similar data ${ }^{27}$. Possible justification for this association is that prolonged sitting or incorrect postures, leading to changes in the musculoskeletal structures of the various body segments, increasing the internal pressure in the nucleus of the intervertebral disc by approximately $35 \%{ }^{1}$. In addition, occurs the stretching of structures (ligaments, small joints and nerves) of the vertebral column, reduction of return circulation of the lower limbs and risk for development of inflammatory processes in the musculoskeletal structures causing symptoms of pain ${ }^{1}$.

As presented in previous studies ${ }^{6,11}$, adolescents who were overweight were more likely to have low levels of lumbar force. This is justified because overweight individuals have lower percentages of muscle mass and the accumulation of central fat promotes the protrusion of the abdomen, leading to distension and weakness of the abdominal musculature, which can result in lower performance in the physical test used.

The variables age, economic level, physical activity level and aerobic fitness did not present significant associations in this study. A study with adolescents from Santa Catarina, Brazil, also found no significant association between low lumbar force levels and the variables age, economic level and level of physical activity. Possible justification is other different lifestyle factors were analysed in other researches, among them dietary habits 5 , Body Mass Index ${ }^{6}$ and sitting time 1 , may have influenced the result.

The limitations of the research were: 1) The fact that the adolescents knew that they were participating in lifestyle research could, in itself, have influenced the results, such as underestimation or overestimation of these variables; 2) Since it was not possible to control the movement of adolescents before the aerobic fitness test, some of them may have started the heart rate test above resting heart rate. 
The relevant finding of this study is factors associated with low level of lumbar force in adolescents, such as excessive screen time and excess weight, are considerable modifiable factors. Thus, different levels of actions aimed at student health can be used to reverse this situation. Effective intervention programs that prioritize the promotion and maintenance of satisfactory levels of lumbar force are required1, especially by encouraging the practice of physical activity ${ }^{6-8}$ and food re-education ${ }^{5}$ to reduce excess body adiposity ${ }^{12}$.

In conclusion, almost half of adolescents presented low levels of lumbar force. Female adolescents and male students who were overweight were more likely to have low levels of lumbar force.

\section{REFERENCES}

1. Zapater AR, Silveira DM, Vitta A, Padovani CR, Silva JCP. Seat posture: the efficiency of an educational program for scholars. Ciênc Saúde Coletiva. 2004;9(1):191-9. DOI: http://dx.doi.org/10.1590/S1413-81232004000100019

2. Hoy D, March L, Brooks P, Blyth F, Woolf A, Bain C, et al. The global burden of low back pain: estimates from the Global Burden of Disease 2010 study. Ann Rheum Dis. 2014;73(6):968-74. DOI: http://dx.doi.org/10.1136/annrheumdis-2013-204428

3. King S, Chambers CT, Huguet A, MacNevin RC, McGrath PJ, Parker L, et al. The epidemiology of chronic pain in children and adolescents revisited: a systematic review. Pain. 2011;152(12):2729-38. DOI: http://dx.doi.org/10.1016/j.pain.2011.07.016

4. Nascimento PRC, Costa LOP. Prevalência da dor lombar no Brasil: uma revisão sistemática. Cad Saúde Pública. 2015; 31(6):1141-55. DOI: http://dx.doi.org/10.1590/0102-311X00046114

5. Perry MC, Straker LM, Oddy WH, O’Sullivan PB, Smith AJ. Spinal pain and nutrition in adolescents - an exploratory cross-sectional study. BMC Musculoskeletal Disord. 2010; 11:138. DOI: http://dx.doi.org/10.1186/1471-2474-11-138

6. Silva DAS, Gonçalves ECA, Grigollo LR, Petroski EL. Factors associated with low levels of lumbar strength in adolescents in Southern Brazil. Rev Paul Pediatr. 2014;32(4): 360-6. DOI: http://dx.doi.org/10.1590/S0103-05822014000400012

7. Yu YL, Su TK, Liaw LJ, Wu WL, Chu IH, Guo LY. The effect of six weeks of sling exercise training on trunk muscular strength and endurance for clientes with low back pain. J Phys Ther Sci. 2015;(8):25916. DOI: http://dx.doi.org/10.1589/jpts.27.2591

8. Yahiaa A, Jribi S, Ghroubi S, Elleuchb M, Baklouti S, Habib EM. Evaluation of the posture and muscular strength of the trunk and inferior members of patients with chronic lumbar pain. Joint Bone Spine. 2011;78(3):291-7. DOI: http://dx.doi.org/10.1016/j.jbspin.2010.09.008

9. Lee JH, Hoshino Y, Nakamura K, Kariya Y, Saita K, Ito K. Trunk muscle weakness as a risk factor for low back pain. A 5 year prospective study. Spine (Phila Pa 1976). 1999;24(1):54 7. DOI: http://dx.doi.org/10.1097/00007632-199901010-00013

10. Vital E, Melo MJ, Nascimento AR, Roque A. Raquialgias na entrada da adolescência: estudo dos factores condicionantes em alunos do $5^{\circ}$ ano. Rev Port Saude Publica. 2006;24(1):57-84.

11. Pondofe KM, Meyer PF, Andrade MCC , Silva EMS. Relationship between abdominal force, abdominal protusion and lobossacral angle in young women. Fisioter Mov 2006;19(4):99-104.

12. Soares Ferreira F, Ramos Duarte JA. Overweight, obesity, physical activity, cardiorespiratory and muscular fitness in a Portuguese sample of high school adolescents. Minerva Pediatr. 2013;65(1):83-91.

13. Thackeray A, Fritz JM, Childs JD, Brennan GP. The Effectiveness of Mechanical Traction Among Subgroups of Patients With Low Back Pain and Leg Pain: A Randomized Trial. J Orthopaedic Sports Phys Therapy. 2016;46(3):144-56. DOI: http://dx.doi.org/10.2519/jospt.2016.6238

14. Canadian Society for Exercise Physiology. The Canadian Physical Activity, Fitness \& Lifestyle Approach: CSEP - Health-Related Appraisal \& Counseling Strategy. In: Physiology CSfE, editor. 3 ed: Canadian Society for Exercise Physiology; 2003.

15. Demoulin C, Vanderthommen M, Duysens C, Crielaard JM. Pinal muscle evaluation using the Sorensen test: a critical appraisal of the literature. Joint Bone Spine. 2006;73(1):43-50. DOI: http://dx.doi.org/10.1016/j.jbspin.2004.08.002

16. Guedes DP, Lopes CC. Validação da versão brasileira do Youth Risk Behavior Survey 2007. Rev Saude Publ. 2010;44(5):840-850. DOI: http://dx.doi.org/10.1590/S0034-89102010000500009

17. American Academy of Pediatrics. Children, Adolescents, and television. Pediatrics. 2001;107(2):423-6. DOI: http://dx.doi.org/10.1542/peds.107.2.423

18. Weller IM, Thomas SG, Gledhill N, Paterson D, Quinney A. A study to validate the modified Canadian Aerobic Fitness Test. Can J Appl Physiol. 1995;20(2):211-21.

19. Gonçalves ECA, Silva DAS. Factors associated with low levels of aerobic fitness among adolescents. Rev Paul Pediatr. 2016;34(2):141-7. DOI: http://dx.doi.org/10.1016/j.rpped.2015.06.015

20. Gonçalves ECA, Silva DAS. Baixos níveis de aptidão aeróbia em adolescentes de 
uma cidade do sul do Brasil. Rev Medicina (Ribeirão Preto). 2016;49(3):202-11.

DOI: http://dx.doi.org/10.11606/issn.2176-7262.v49i3p202-211

21. Silva DA, Tremblay M, Pelegrini A, Silva RJS, Oliveira ACC, Petroski EL. Association Between Aerobic Fitness And High Blood Pressure in Adolescents in Brazil: Evidence for Criterion-Referenced CutPoints. Pediatr Exerc Sci. 2016;28(2):312-20. DOI: http://dx.doi.org/10.1123/pes.2015-0172

22. Onis M, Onyango AW, Borghi E, Siyam A, Nishida C, Siekmann J. Development of a WHO growth reference for school-aged children and adolescents. Bull World Health Organ. 2007;85(9):660-7. DOI: http://dx.doi.org/10.1590/S0042-96862007000900010

23. Lemos AT, Santos FR, Moreira RB, Machado DT, Braga FC, Gaya AC. Low back pain and associated factors in children and adolescents in a private school in Southern Brazil. Cad Saude Publica. 2013;29(11):2177-85. http://dx.doi.org/10.1590/0102-311x00030113

24. Malina RM. Adherence to physical activity from childhood to adulthood: a perspective from tracking studies. J Quest. 2001;53(3):346-55. DOI: http://dx.doi.org/10.1080/00336297.2001.10491751

25. Shan Z, Deng G, Li J, Li Y, Zhang Y, Zhao Q. Correlational analysis of neck/shoulder pain and low back pain with the use of digital products, physical activity and psychological status among adolescents in Shanghai. Plos One. 2013;8(10):e78109. DOI: http://dx.doi.org/10.1371/journal.pone.0078109

26. Alves Junior CAS, Nunes HEG, Gonçalves ECA, Silva DAS. Suicidal behaviour in adolescents: Characteristics and prevalence. J Hum Growth Dev. 2016;26(1):88-94. DOI: http://dx.doi.org/10.7322/jhgd.113733

27. Maldonado G, Greenland S. Simulation study of confounder-selection strategies. Am J Epidemiol. 1993;138(11):923-36. DOI: http://dx.doi.org/10.1093/oxfordjournals.aje.a116813

\section{Resumo}

Introdução: A lombalgia é uma doença multifatorial e é um dos desconfortos musculoesqueléticos mais comuns.

Objetivo: Assim, o objetivo é analisar os fatores associados e estimar a prevalência de baixos níveis de força lombar em adolescentes.

Método: Trata-se de um estudo transversal, com 909 adolescentes de 14 a 19 anos, estudantes de escolas públicas da cidade de São José, Santa Catarina - Brasil. Analisou-se a força lombar por meio do teste de extensão lombar proposto pela Canadian Physical Activity, Fitness and Lifestyle Approach (CPAFLA) que propõe pontos de corte distintos para os sexos. As variáveis independentes analisadas foram: sexo, idade, nível econômico, tempo de tela, atividade física, aptidão aeróbia e Indíce de Massa corporal. Para a análise dos dados utilizou-se a regressão logística binária com nível de significância de $5 \%$.

Resultados: A prevalência de baixos níveis de força lombar foi de $45,2 \%$, sendo $36,2 \%$ para os meninos e $53,1 \%$ para as meninas. Os subgrupos populacionais com maiores chances de baixos níveis de força lombar foram o sexo feminino (OR: 1,99; IC95\%: 1,52-2,60) e adolescentes com excesso de peso (OR: 1,48; IC95\%: $1,12-1,96)$.

Conclusão: Quase metade dos estudantes apresentaram baixos níveis de força lombar. As meninas, os adolescentes com excesso de peso e os com tempo excessivo à frente da tela estiveram mais propícios a terem baixos níveis de força lombar. A novidade desse artigo é que fatores modificáveis, como o tempo de tela excessivo e o excesso de peso podem ser preteridos em intervenções de promoção da saúde que visem aprimorar os níveis de força dos jovens.

Palavras-chave: atividade motora, aptidão física, lombalgia, saúde do adolescente, coluna vertebral, dor

- The authors (2017), this article is distributed under the terms of the Creative Commons Attribution 4.0 International License (http://creativecommons.org/licenses/by/4.0/), which permits unrestricted use, distribution, and reproduction in any medium, provided you give appropriate credit to the original author(s) and the source, provide a link to the Creative Commons license, and indicate if changes were made. The Creative Commons Public Domain Dedication waiver (http://creativecommons.org/publicdomain/ zero/1.0/) applies to the data made available in this article, unless otherwise stated. 